\title{
Effect of Cataract Surgery on Intraocular Pressure in Glaucoma Patients
}

\author{
Shua Azam ${ }^{1}$, Abdul Hameed Talpur², Mahak Shaheen ${ }^{3}$, Sadia Bukhari ${ }^{4}$ \\ ${ }^{1-3}$ ISRA School of Optometry, Al-Ibrahim Eye Hospital, Karachi \\ ${ }^{4}$ Department of Ophthalmology, Al-Tibri Medical College
}

\begin{abstract}
Purpose: To determine the change in intraocular pressure after cataract surgery in patients diagnosed with glaucoma.

Study Design: Interventional case series.

Place and Duration of Study: Glaucoma Clinic. Al-lbrahim Eye Hospital (AIEH) Karachi, Pakistan from May to October, 2019.

Methods: Thirty-eight patients diagnosed with glaucoma and cataract and registered in glaucoma clinic were recruited for this study. Inclusion Criteria was age $>41$ years and patients diagnosed with primary open/closed angle glaucoma and cataract. Patients with secondary glaucoma, history of trabeculectomy and any other ocular diseases were excluded from the study. Pre-operative assessment was done for phacoemulsification. In postoperative examination, first and second follow-up IOP was measured. Data analysis was done on statistical package for social science (SPSS) version 20.0. Statistical changes were present in the form of bar chart, frequency and graphs. The mean standard deviation for pre-operative, post-operative 1st and 2nd follow-up IOP was calculated.

Results: A total of 38 participants and 48 eyes satisfied the inclusion criteria. Out of 48 eyes, $39(81.3 \%)$ eyes were diagnosed with Primary open angle glaucoma and 9 (18.8\%) eyes with Primary Angle Closure Glaucoma. The pre-operative mean IOP was $16.56 \pm 6.67 \mathrm{~mm} \mathrm{Hg}$ and post-operative mean IOP at first follow-up was $13.39 \pm$ $4.04 \mathrm{~mm} \mathrm{Hg}$. At second follow-up at one-month mean IOP was $12.14 \pm 2.28 \mathrm{~mm} \mathrm{Hg}$.
\end{abstract}

Conclusion: Phacoemulsification produces a useful decrease in IOP in glaucoma patients.

Key Word: Glaucoma, Cataract, Phacoemulsification, Intraocular Pressure.

How to Cite this Article: Azam S, Talpur AH, Shaheen M, Bukkhari S. Effect of Cataract Surgery on Intraocular Pressure in Glaucoma Patients. Pak J Ophthalmol. 2021, 37 (1): 62-65.

Doi: https://doi.org/10.36351/pjo.v37i1.1167

\section{INTRODUCTION}

The global prevalence of glaucoma in 40 - 80 years old patients is $3.54 \%{ }^{1}$ The prevalence of Primary open

Correspondence: Shua Azam

ISRA School of Optometry

Al-Ibrahim Eye Hospital, Karachi

Email: optomshuaazam@gmail.com

Received: October 17, 2020

Accepted: November 30, 2020 angle glaucoma (POAG) is highest in Africa and the prevalence of Primary angle closure glaucoma (PACG) is highest in Asia. People of European ancestry and people living in urban areas are more likely to have POAG than those in rural areas. ${ }^{1}$ In Pakistan, POAG is the most common type followed by primary angle closure, aphakic, secondary and congenital glaucoma. ${ }^{2}$ Cataract surgery may alter IOP and several studies have reported these changes, which include increased IOP, decreased IOP and even hypotony. ${ }^{3}$ Cataract surgery has been shown to reduce IOP in eyes with or without glaucoma. ${ }^{4}$ In eyes with 
angle closure glaucoma (ACG), phacoemulsification is an effective procedure in lowering intra-ocular pressure (IOP). In eyes with open angle glaucoma (OAG) a decline in IOP is also seen. ${ }^{5}$ Higher preoperative IOP, shallow anterior chamber and higher preoperative IOP were reported to be the indicators of more prominent IOP drop after surgery. ${ }^{6}$

This interventional case series was carried out to see the drop in intraocular pressures in cases of primary open glaucoma and primary closed glaucoma following phacoemulsification.

\section{METHODS}

Patients diagnosed with glaucoma and cataract were registered in glaucoma clinic for detailed assessment. Inclusion Criteria was male or female patients with age more than 41 years and patients diagnosed with primary open/closed angle glaucoma and cataract. Patient diagnosed with pseudoexfoliation, history of trabeculectomy or retinal surgery, other ocular disease and secondary glaucoma were excluded. Pre-operative assessment was done and in the post-operative followup, IOP was measured at one week and one month using Goldmann Applanation Tonometer. Data analysis was done on statistical package for social science (SPSS) version 20.0. The mean standard deviation for pre-operative and post-operative IOP at first and second follow-up was calculated.

\section{RESULTS}

The study included age group from 41 to 70 years old and the mean age was 54.72 years. There were 22 eyes from male patients and 26 eyes from female patients. Out of 48 eyes, $39(81.3 \%)$ eyes were diagnosed with POAG and $9(18.8 \%)$ eyes with PACG. The preoperative mean IOP was $16.65 \pm 6.67 \mathrm{~mm} \mathrm{Hg}$ and the mean IOP for first post-operative follow-up at week one was $13.39 \pm 4.04 \mathrm{~mm} \mathrm{Hg}$. Out of 48 eyes, only 34 eyes presented for second follow-up at one month when the mean IOP was $12.14 \pm 2.28 \mathrm{~mm} \mathrm{Hg}$. The pre-operative IOP was in the range of $8-30 \mathrm{~mm} \mathrm{Hg}$ which was reduced to $9-20 \mathrm{~mm} \mathrm{Hg}$ on first postoperative follow-up which was further reduced to $9-$ $15 \mathrm{~mm} \mathrm{Hg}$ on second post-operative follow-up at one month.

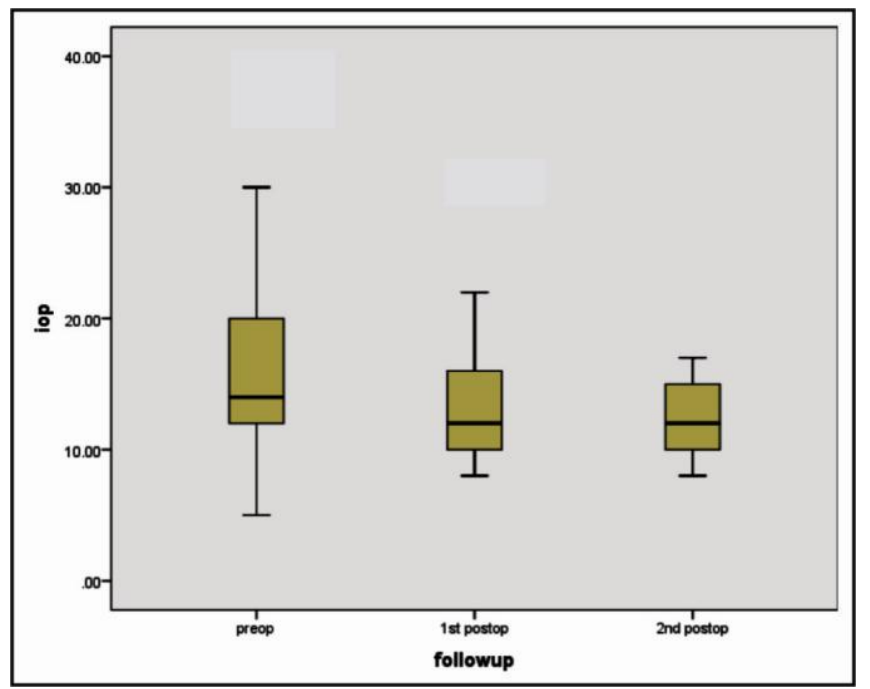

Graph 1: Changes in IOP $(\mathrm{mmHg})$ at one and four weeks after phacoemulsification with intraocular lens implantation.

\section{DISCUSION}

Our results co-relate with a study conducted in Sankara eye care institution in India in which they took a retrospective interventional case series of 218 patients which included 120 females and 98 males and all patients underwent phacoemulsification surgery. They recorded change in IOP for operated and fellow eye. They found a mean reduction in IOP in operated eye with a $P$ value of 0.004 . $^{7}$ Some other studies showed same results that IOP significantly decreased after phacoemulsification. ${ }^{8}$

Different Studies have reported that cataract extraction alone lowers IOP two to four $\mathrm{mm} \mathrm{Hg}$ which correlates with our results. In patients with higher preoperative IOP the reduction in IOP was more significant. ${ }^{1}$ Other studies showed that addition to preoperative IOP and lens thickness, parameters like changes in anterior chamber area and angle opening distance were also significantly associated with reduction in IOP after phacoemulsification. ${ }^{10,11}$ These factors were not studied in our research. Pre-operative IOP was the sole factor significantly related to postoperative IOP reduction after cataract surgery in POAG patients. High pre-operative IOP was strongly related to a greater postoperative IOP reduction. Patients with low pre-operative IOPs have minimal reduction or perhaps a gentle increase in postoperative IOPs while our study did not categorize preoperative IOPs. ${ }^{12}$

Some studies reported that Phacoemulsification resulted in a very small average decrease in IOP in 
patients with open angle glaucoma. A sizeable proportion of medically controlled glaucoma patients with open angles undergoing phacoemulsification experienced a rise in IOP or required more aggressive treatment to regulate IOP postoperatively. ${ }^{13,14}$ In contrast to this, our study did not take into account the pre-operative medical treatment of glaucoma into consideration.

Various studies have shown that combined glaucoma/cataract surgery results in more IOP reduction as compared to cataract surgery alone. Our study took phacoemulsification alone into consideration. ${ }^{15,16}$

Both surgical and medical treatment of glaucoma increase the risk for cataract development. Phacoemulsification (PE) in any case, can be actually more challenging in glaucoma patients due to visual conditions such as the exfoliation syndrome, a past episode of acute Angle closure or a history of past ocular surgeries, miotic treatment, injury, or uveitic glaucoma. In some situations, uncomplicated PE alone may serve to decrease the long-term intraocular pressure. ${ }^{16,17}$ However, our study did not take into consideration the treatment strategy of glaucoma.

Systematic review and meta-analysis of the clinical data showed net effect of cataract surgery on IOP reduction. For angle-closure glaucoma, there was reduction in IOP for about $-6.4 \mathrm{~mm} \mathrm{Hg}$ (95\% CI: -9.4 to -3.4$)$ at final follow-up (12 months and longer) while for the open-angle glaucoma group, there was an overall IOP change of $-2.7 \mathrm{~mm} \mathrm{Hg}$ (95\% CI -3.7 to 1.7) from baseline. ${ }^{18}$ These results are consistent with our study findings.

Cataract surgery decreases IOP in patients with ocular hypertension over a long period of time but we took only two post-operative follow-ups. ${ }^{19}$ Another study reported that the mean decrease in IOP and percentage of IOP reduction in the angle closure glaucoma (ACG) group were greater than in the open angle glaucoma (OAG) group. However, our study findings showed overall reduction for the both types of glaucoma. ${ }^{20}$

Other study revealed that phacoemulsification done on glaucomatous eyes results in lowering of $1 O P$ but the dosage of glaucoma drugs over the long term should be simplified or even discontinued. ${ }^{21}$

Lancu et al reported that intraocular pressure
(IOP) phacoemulsification in patients with uncontrolled
POAG, but the decrease was not adequate for optimal glaucoma management and many patients needed subsequent glaucoma surgery but our study did not focus on the treatment regimen of glaucoma. ${ }^{22}$ Legrand et al. compared intraocular pressure (IOP) during the first month following cataract surgery among patients with primary open-angle glaucoma (POAG) and nonglaucomatous patients. They found raised IOP in POAG patients than non-glaucomatous patients while our study did not include healthy individuals. ${ }^{23}$

Limitation of our study was that we did not take into account other factors which affect IOP including anterior chamber depth, pre-operative medications and lens thickness. Secondly the sample size was small and a single center was involved in this study. Further follow-ups are also needed to comment on the long term effects on the IOP after phacoemulsification.

\section{CONCLUSION}

Phacoemulsification produces a useful decrease in IOP in glaucoma patients.

\section{Ethical Approval}

The study was approved by the Institutional review board/ Ethical review board. (REC/IPIO/2020/006)

\section{Conflict of Interest}

Authors declared no conflict of interest.

\section{REFERENCES}

1. Yih-Chung T, Xiang Li, Tien YW. Global Prevalence of Glaucoma and Projections of Glaucoma. Am J Ophthalmol. 2014; 121 (11): 2081-2090.

2. Tariq M, Jafri W, Ansari T, Awan S, Ali F, Shah M, et al. Medical mortality in Pakistan: experience at a tertiary care hospital. Postgrad Med J. 2009; 85 (1007): 470-474. Doi: 10.1136/pgmj.2008.074898.

3. Shingleton B, Rosenberg R, Teixeira R. Evaluation of intraocular pressure in the immediate postoperative period after phacoemulsification. J Cataract Refract Surg. 2007; 33 (11): 1953-1957.

4. Poley B, Lindstrom R, Samuelson T. Intraocular pressure reduction after phacoemulsification with intraocular lens implantation in glaucomatous and nonglaucomatous eyes: Evaluation of a causal relationship between the natural lens and open-angle glaucoma. J Cataract Refract Surg. 2009; 35: 1946-1955. 
5. Chen PP, Lin SC, Junk AK, Radhakrishnan S, Singh K, Chen TC. The Effect of Phacoemulsification on Intraocular Pressure in Glaucoma Patients: A Report by the American Academy of Ophthalmology. Ophthalmology, 2015; 122 (7): 1294-1307.

Doi: 10.1016/j.ophtha.2015.03.021.

6. Issa SA, Pacheco J, Mahmood U, Nolan J, Beatty S. A novel index for predicting intraocular pressure reduction following cataract surgery. Br J Ophthalmol. 2005; 89 (5): 543-546. Doi: 10.1136/bjo.2004.047662.

7. Kumar S, Ajita S. Analysis of change in intraocular pressure after phacoemulsification. Sudan J Ophthalmol. 2013; 5 (01): 7-8.

8. Baek SU, Kwon S, Park IW, Suh W. Effect of Phacoemulsification on Intraocular Pressure in Healthy Subjects and Glaucoma Patients. J Korean Med Sci. 2019; 34 (6): e47. Doi: 10.3346/jkms.2019.34.e47.

9. Friedman DS, Jampel HD, Lubomski LH, Kempen JH, Quigley H, Congdon N, et al. Surgical strategies for coexisting glaucoma and cataract: an evidencebased update. Ophthalmology, 2002; 109: 1902-1913.

10. Hyun SY, Lee J, Choi S. Ocular Biometric Parameters Associated With Intraocular Pressure Reduction after Cataract Surgery in Normal Eyes. Am J Ophthalmol. 2013; 156 (1): 89-94.

11. Bilak S, Simsek A, Capkin M, Guler M, Bilgin B. Biometric and intraocular pressure change after cataract surgery. Optom Vis Sci. 2015; 92 (4): 464-470.

Doi: 10.1097/OPX.0000000000000553.

12. Guan H, Mick A, Porco T, Dolan BJ. Preoperative factors associated with IOP reduction after cataract surgery. Optom Vis Sci. 2013; 90 (2): 179-184.

Doi: 10.1097/OPX.0b013e31827ce224.

13. Slabaugh MA, Bojikian KD, Moore DB, Chen PP. The effect of phacoemulsification on intraocular pressure in medically controlled open-angle glaucoma patients. Am J Ophthalmol. 2014; 157 (1): 26-31.

Doi: 10.1016/j.ajo.2013.08.023

14. Majstruk L, Leray B, Bouillot A, Michée S, Sultan G, Baudouin C, et al. Long term effect of phacoemulsification on intraocular pressure in patients with medically controlled primary open-angle glaucoma. BMC Ophthalmol. 2019; 19 (1): 149.

15. Rehman MA, Khairy HA, Azuara-Blanco A. Effect of cataract extraction on SITA perimetry in patients with glaucoma. J Glaucoma, 2007; 16: 205-208.
16. Friedman DS, Jampel HD, Lubomski LH, Kempen JH, Quigley H, Congdon N, et al. Surgical strategies for coexisting glaucoma and cataract: an evidencebased update. Ophthalmology, 2002; 109: 1902-1913.

17. Rehman MA, Khairy HA, Azuara-Blanco A. Effect of cataract extraction on SITA perimetry in patients with glaucoma. J Glaucoma, 2007; 16: 205-208.

18. Maire M, Patrick M, Eileen P, Shan CL. The role of phacoemulsification in glaucoma therapy: A systematic review and meta-analysis. Surv Ophthalmol.2018; 63(5):700-710.

Doi: 10.1016/j.survopthal.2017.08.006.

19. Steven L, Mae O, Henry J, et al. Reduction in intraocular pressure after cataract extraction: The ocular hypertension treatment study. Ophthalmology. 2012: 119(9):1826-1831.Doi: 10.1016/j.ophtha.2012.02.050

20. Hayashi K, Hayashi H, Nakao F, Hayashi F. Effect of cataract surgery on intraocular pressure control in glaucoma patients. J Cataract Refract Surg. 2001; 27:1779-86.

21. Mierzejewski A, Eliks I, Kałuzny B, Zygulska M, Harasimowicz B, Kaluzny JJ. Cataract phacoemulsification and intraocular pressure in glaucoma patients. Klin Ocz. 2008; 110:11-7.

22. Lancu R, Corbu C. Intraocular pressure after phacoemulsification in patients with uncontrolled primary open angle glaucoma. J Med Life. 2014; 7:11.

23. Legrand M, Blumen-Ohana E, Laplace O, Adam R, Akesbi J, Colas E, et al. Early postoperative intraocular pressure after phacoemulsification: Normal patients versus glaucoma patientsJ Fr Ophthalmol. $2015 ; 38: 633-8$.

\section{Authors' Designation and Contribution}

Shua Azam; Optometrist: Design, Data analysis, Statistical analysis.

Abdul Hameed Talpur; Consultant Ophthalmologist: Concepts, Literature search, Manuscript preparation, Manuscript review.

Mahak Shaheen; Optometrist: Literature search, Data acquisition.

Sadia Bukhari; Professor: Concepts, Manuscript review. 